\title{
A produção científica sobre a Educação Profissional e Tecnológica
}

\section{Scientific production on Professional and Technological Education}

\section{Producción científica en Educación Profesional y Tecnológica}

Silva, Marina Chaves (Belo Horizonte, MG, Brasil) ${ }^{1}$ ORCID ID: https://orcid.org/0000-0003-3874-5844

Ramos, Ivo de Jesus (Belo Horizonte, MG, Brasil) ${ }^{2}$ ORCID ID: https://orcid.org/0000-0002-5731-8904

\section{Resumo}

Este artigo tem como objetivo conhecer o que vem sendo pesquisado e produzido sobre a Educação Profissional e Tecnológica (EPT). Busca-se também entender o que se trata a EPT, sua constituição social, histórica e política no Brasil, identificando os principais autores e legislações que tratam sobre o tema. A abordagem metodológica se descreve como uma pesquisa qualitativa e de caráter exploratório. Os objetos de pesquisa são produções acadêmicas publicadas em periódicos científicos, que, posteriormente foram categorizados e analisados de acordo com a análise de conteúdo para a interpretação dos dados. Foram encontradas sete categorias diferentes de acordo com os temas tratados dentro da Educação Profissional e Tecnológica, propiciando o entendimento de forma mais abrangente sobre a EPT.

Palavras-chave: Educação profissional e tecnológica; Produção científica; Levantamento bibliográfico.

\begin{abstract}
This paper aims to find out what has been researched and produced on Professional and Technological Education (EPT). It also seeks to understand what EPT is about, its social, historical and political constitution in Brazil, identifying the main authors and legislation that deal with the theme. The methodological approach is described as a qualitative and exploratory research. The research objects are academic productions published in scientific journals, which were later categorized and analyzed according to the content analysis for data interpretation. Seven different categories were found according to the themes dealt with within Professional and Technological Education, providing a more comprehensive understanding of EPT.
\end{abstract}

Keywords: Professional and technological education; Scientific production; Bibliographic survey.

\section{Resumen}

Este artículo tiene como objetivo averiguar qué se ha investigado y producido sobre Educación Profesional y Tecnológica (EPT). También busca comprender de qué se trata la EPT, su constitución social, histórica y política en Brasil, identificando los principales autores y la legislación que trata el tema. El enfoque metodológico se describe como una investigación cualitativa y exploratoria. Los objetos de investigación son producciones académicas publicadas en revistas científicas, que luego se clasificaron y analizaron de acuerdo con el análisis de contenido para la interpretación de datos. Se encontraron siete categorías diferentes de acuerdo con los temas tratados dentro de la Educación Profesional y Tecnológica, proporcionando una comprensión más integral de la EPT.

\footnotetext{
1 Técnica em Assuntos Educacionais na Universidade Federal de Minas Gerias. marinacsf11@gmail.com 2 Professor do Ensino Básico Técnico e Tecnológico do Centro Federal de Educação Tecnológica de Minas Gerais (CEFETMG).
} 
Revista Labor

Programa de Pós-graduação em Educação, Universidade Federal do Ceará

Fortaleza-CE-Brasil

Palavras-Clave: Educación profesional y tecnológica; Producción científica; Encuesta bibliográfica.

\section{Introdução}

Este trabalho é o começo de uma caminhada em busca do entendimento sobre a Educação Profissional e Tecnológica e sobre a pesquisa científica produzida a respeito dela. O que é a Educação Profissional e Tecnológica? O que ela abrange? Qual o seu histórico no Brasil? Qual a sua constituição social e política? Quem são as pessoas que estão pesquisando e falando sobre EPT? O que estão pesquisando sobre ela?

Responder a essas perguntas é o primeiro passo para o desenvolvimento de uma pesquisa a respeito dos conceitos de Educação Profissional e Tecnológica. É necessário, primeiramente, entender sobre o que se trata a EPT.

Dessa forma, esse estudo é uma revisão de literatura e tem como objetivo fazer um levantamento das produções científicas sobre a EPT dos últimos anos, de maneira a entender o que vem sendo pesquisado a respeito, o que é a Educação Profissional e Tecnológica e a sua constituição social, histórica e política no Brasil. Além disso, esse levantamento busca identificar os principais autores e legislações que tratam o tema, para construir um referencial teórico que possa contribuir com futuras pesquisas sobre a EPT.

\section{Metodologia}

De forma a identificar, mapear, categorizar, entender e analisar a produção científica referente a Educação Profissional e Tecnológica foi realizado um levantamento dos artigos publicados num período de seis anos, ou seja, de 2014 a 2019, no Portal de Periódicos da Coordenação para o Aperfeiçoamento de Pessoal de Nível Superior (Capes). Para a busca no referido site, foi utilizado o termo Educação Profissional e Tecnológica. Como o resultado da busca apresentou 1292 artigos, delimitou-se a presença do termo no título dos trabalhos e foram selecionados os artigos revisados por pares publicados em periódicos. 
Com esses parâmetros de pesquisa, foram encontrados 33 artigos no total, sendo excluídos quatro repetidos e quatro que disponibilizavam apenas o resumo. Dessa forma, foram tabulados, categorizados e analisados 25 artigos sobre Educação Profissional e Tecnológica.

Para realizar a análise de conteúdo dos trabalhos selecionados foi utilizada como referência Bardin (2016), a qual organiza essa análise em três fases: préanálise, exploração do material e tratamento dos resultados.

A pré-análise é a fase em que ocorre o primeiro contato e a organização do material. Nessa etapa ocorre a escolha dos documentos por regras que delimitam e produzem o corpus do estudo. Além disso, utiliza-se de uma leitura flutuante para estabelecer esse primeiro contato com o material e prepará-lo para a exploração. A próxima fase da análise é a exploração do material, onde o corpus é categorizado e classificado de acordo com uma codificação que, por sua vez, só é possível com uma leitura mais aprofundada desse material. Finalmente, a última etapa da análise é o tratamento dos resultados, onde os dados são trabalhados e são feitas inferências e interpretações a respeito do que trata esse corpus de estudo.

Tendo em vista os objetivos desse levantamento, foi realizada primeiramente a pré-análise do material e o fichamento de cada um dos trabalhos selecionados para extrair informações gerais como o título, o ano de publicação, os autores e suas instituições de origem, a revista na qual o trabalho foi publicado, o resumo e as palavras-chave desses artigos. Para isso, foi elaborada uma planilha de mapeamento onde, por meio de uma leitura flutuante, foi possível obter esses dados.

As outras informações mais específicas como objetivo e foco do estudo, metodologia, aportes teórico-metodológicos e resultados foram obtidas fazendo-se uma exploração do material com uma leitura mais aprofundada do mesmo.

Devido aos objetivos desse estudo, a análise realizada é qualitativa, uma vez que não se busca a frequência de aparição de determinados elementos da mensagem, e sim a presença ou não desses elementos e o que se diz sobre eles. Além disso, trata-se de uma pesquisa com o caráter exploratório. De acordo com 
Lakatos e Marconi (2003), a pesquisa exploratória tem o objetivo de "aumentar a familiaridade do pesquisador com um ambiente, fato ou fenômeno, para a realização de uma pesquisa futura mais precisa ou modificar e clarificar conceitos" (p. 188). Essa pesquisa busca, portanto, entender o que se trata a Educação Profissional e Tecnológica e conhecer o que vem sendo pesquisado e produzido sobre a EPT.

\section{Produção científica sobre Educação Profissional E Tecnológica}

Nessa seção analisaremos os artigos selecionados na intenção de entender sobre a produção científica com relação a Educação Profissional e Tecnológica.

De acordo com Vosgerau e Romanowski (2014), as revisões de literatura são importantes para auxiliar pesquisadores que estão iniciando a pesquisa em determinada área, podendo conter análises sobre focos temáticos, evolução de teorias, aportes teórico metodológicos, procedimentos metodológicos e tendências das abordagens. Além disso, os estudos podem ser organizados também pelos objetivos ou problemas investigados ou pelos resultados e lacunas encontradas nos trabalhos e que possam estimular novos estudos.

Este trabalho organiza os artigos selecionados de acordo com seus focos temáticos, de maneira a entender sobre os assuntos investigados nos trabalhos científicos publicados no período de 2014 a 2019 a respeito da Educação Profissional e Tecnológica.

Classificar as publicações encontradas de acordo com os focos temáticos permite encontrar pontos de convergência e tendências de pesquisas sobre a Educação Profissional e Tecnológica, propiciando o entendimento de forma mais abrangente sobre o tema estudado.

O Quadro 1 apresenta o resultado da categorização dos 25 artigos selecionados sobre EPT.

Quadro 1: Categorização dos artigos de acordo com os focos temáticos 
Revista Labor

Programa de Pós-graduação em Educação, Universidade Federal do Ceará

Fortaleza-CE-Brasil

\begin{tabular}{|c|c|}
\hline Foco Temático & Autores/Ano de publicação \\
\hline $\begin{array}{l}\text { Configuração, constituição e } \\
\text { transformação histórica, social e política } \\
\text { da Educação Profissional e Tecnológica }\end{array}$ & $\begin{array}{c}\text { Afonso, Gonzalez (2015); Rosa, Amorim, Macedo (2015); Afonso, } \\
\text { Gonzalez (2016); Ciavatta (2016); Oliveira, Matta (2017); Costa } \\
\text { (2019a); Costa (2019b) }\end{array}$ \\
\hline $\begin{array}{c}\text { Formação profissional e perfil do } \\
\text { docente na Educação Profissional e } \\
\text { Tecnológica }\end{array}$ & $\begin{array}{c}\text { Carvalho, Souza (2014); Campos et al (2015); Pinheiro et al } \\
\text { (2015); Souza (2017); Souza, Souza (2018) }\end{array}$ \\
\hline $\begin{array}{l}\text { Gestão da Rede Federal de Educação } \\
\text { Profissional e Tecnológica }\end{array}$ & $\begin{array}{l}\text { Rosa, Massukado, Stumpf (2015); Beltrame, Alperstedt (2015); } \\
\text { Araújo, Hypólito (2016); Mello, Melo, Mello Filho (2016); Nunes, } \\
\text { Souza (2018) }\end{array}$ \\
\hline $\begin{array}{l}\text { Recursos utilizados na Educação } \\
\text { Profissional e Tecnológica }\end{array}$ & Nascimento, Rodrigues (2014); Freitas, Duarte Filho (2018) \\
\hline $\begin{array}{l}\text { Atuação de psicólogos na Educação } \\
\text { Profissional e Tecnológica }\end{array}$ & Feitosa, Araújo (2018); Titon, Zanella (2018) \\
\hline $\begin{array}{l}\text { Produções da Educação Profissional e } \\
\text { Tecnológica }\end{array}$ & $\begin{array}{l}\text { Prado, Fernandez-Crehuet (2017); Pasqualli, Vieira, Castaman } \\
\qquad(2018)\end{array}$ \\
\hline $\begin{array}{c}\text { Avaliação da Educação Profissional e } \\
\text { Tecnológica }\end{array}$ & Korb, Andrade, Freire (2019); Souza et al (2019) \\
\hline
\end{tabular}

Fonte: os autores

As publicações foram organizadas em sete categorias diferentes de acordo com os temas tratados dentro da Educação Profissional e Tecnológica e serão discutidas separadamente.

\subsection{Configuração, constituição e transformação histórica, social e política da}

\section{Educação Profissional e Tecnológica}

Apesar de apenas sete trabalhos tratarem especificamente sobre configuração, constituição ou transformação da Educação Profissional e Tecnológica e serem enquadrados no primeiro foco temático, a maioria dos artigos selecionados apresentam uma contextualização sobre a EPT, com o cenário social, político e/ou econômico. Por esse motivo, todos os estudos encontrados auxiliam na análise e compreensão desse foco temático.

A história da Educação no Brasil está intimamente ligada a realidade econômica e social que a produziu em cada época. Ou seja, para compreender os 
projetos educacionais ao longo do tempo, é preciso entender um pouco sobre as relações e embates que perpassavam cada momento. Dessa maneira, para compreender a configuração da Educação Profissional e Tecnológica e suas transformações ao longo da história brasileira, é importante analisá-la juntamente com a realidade do país ao longo do tempo.

Oliveira e Matta (2017) fazem essa análise, apresentando uma abordagem histórica da Educação Profissional e Tecnológica (EPT) no Brasil desde a Primeira República (1889-1930) até o ano de 2010. As autoras elucidam, por meio de uma revisão bibliográfica, os impactos causados na EPT de acordo com os governos e as disputas de diferentes projetos de sociedade em cada época, refletindo nas políticas públicas implementadas.

Ciavatta (2016) e Costa (2019a) também analisam a EPT de acordo com a realidade do país. Ciavatta (2016) reflete sobre a configuração do campo da Educação Profissional e Tecnológica, levando em conta algumas políticas educacionais voltadas para essa modalidade de ensino. Já Costa (2019a) trata sobre a constituição da Educação Profissional e Tecnológica nas décadas de 1990 e 2000, com uma abordagem sócio histórica.

Costa (2019b) também apresenta a articulação entre o trabalho na visão marxista com a Educação Profissional e Tecnológica no Brasil. Nesse seu estudo, o autor discute sobre a EPT no sistema capitalista de produção, voltada para uma formação tecnicista, e sobre a EPT como uma proposta de formação integral do trabalhador.

Rosa, Amorim e Macedo (2015) apresentam a contextualização de um Instituto Federal em relação às políticas de Educação Profissional e Tecnológica; e Afonso e Gonzalez $(2015,2016)$ debatem, nos dois trabalhos, sobre a EPT com análises e perspectivas de leis, documentos oficiais e do Plano Nacional da Educação.

Para Afonso e Gonzalez (2016), Ciavatta (2016) e Costa (2019b) a Educação Profissional e Tecnológica apresenta contradições ao longo de toda a sua história, influenciada por diferentes concepções de formação e configuração: uma 
educação voltada para atender o mercado de trabalho e preparar para as exigências da produção capitalista, numa configuração tecnicista e produtivista, ou uma educação enquanto espaço de conhecimento e de transformação, voltada para uma formação humanista e integral do trabalhador. Cada governo ou política pública implementada reforça ou não um desses dois tipos de configuração da EPT (OLIVEIRA; MATTA, 2017).

Os trabalhos encontrados que apresentam a história da Educação Profissional e Tecnológica relatam que a origem da Rede Federal de Educação Profissional e Tecnológica foi em 23 de setembro de 1909, quando Nilo Peçanha, então Presidente do Brasil, assinou o Decreto 7566, determinando a criação de dezenove Escolas de Aprendizes e Artífices em diferentes estados, com o objetivo de ofertar o ensino profissional, primário e gratuito à população (BRASIL, 2009). De acordo com Oliveira e Matta (2017), essas primeiras instituições de ensino profissional foram criadas devido a preocupação do Estado em combater o ócio daqueles que não encontravam nenhuma colocação, os chamados "desvalidos" e "desfavorecidos da fortuna", que eram potenciais ameaçadores da ordem. Além disso, as políticas públicas da época, se voltavam para a formação de operários que atendessem a demanda de mão de obra para atendimento às fábricas que, no início do século 20, estavam se estabelecendo no Brasil (ROSA; AMORIM; MACEDO, 2015).

Segundo Oliveira e Matta (2017), é a partir do governo de Getúlio Vargas (1930-1945), que o Brasil acelera o processo de industrialização e modernização, de forma que as políticas educacionais se voltam cada vez mais para atender a necessidade de formar trabalhadores para as indústrias. Também, é a partir dessa época, chamada de Nova República do Presidente Vargas, que os segmentos empresariais tomam a frente na formação profissional dos trabalhadores (CIAVATTA, 2016). Costa (2019b) destaca a criação do Sistema "S", na década de 1940, como forma de acelerar a preparação de mão de obra para o mercado de trabalho, indústria e comércio.

Entre os anos de 1942 e 1959, as Escolas Industriais e Técnicas foram as 
responsáveis por ofertar cursos que atendessem os interesses dos setores industriais e tecnológicos brasileiros dentro de um panorama socioeconômico que se apresentava promissor no país (FEITOSA; ARAÚJO, 2018).

Em 1959, sob o governo de Juscelino Kubitschek, que foi marcado pela intensificação da relação do Estado com a economia (CAMPOS ET AL., 2015), as Escolas Industriais e Técnicas são transformadas em Escolas Técnicas Federais, aumentando a formação de mão de obra qualificada diante da demanda industrial (NASCIMENTO; RODRIGUES, 2014).

Já em 1971, com o espaço democrático ausente, a Lei de Diretrizes e Bases da Educação Brasileira - LDB 5692/1971 torna obrigatório o ensino técnicoprofissional em todo currículo do segundo grau, hoje Ensino Médio, de maneira a formar técnicos sob o regime da urgência (CAMPOS ET AL., 2015). Para Nascimento e Rodrigues (2014), esse foi um importante fato para a consolidação da Educação Profissional e Tecnológica no Brasil.

Até a década de 1990, de acordo com Costa (2019b), a Educação Profissional e Tecnológica configurou-se como uma proposta de formar trabalhadores para o setor privado da economia, com um caráter tecnicista, visando o fortalecimento do lucro e do capital do empresariado.

Os anos 1990 são marcados por transformações sociais que promovem novas práticas educacionais. Segundo Ciavatta (2016), nessa década são implantadas políticas neoliberais em todos os campos, inclusive na educação. Em 1994, a Lei 8.948/1994 instituiu o Sistema Nacional de Educação Tecnológica, iniciando mudanças que levaram à criação da Rede Federal de Educação Profissional e Tecnológica (NASCIMENTO; RODRIGUES, 2014).

Com a promulgação da Lei de Diretrizes e Bases da Educação Brasileira LDB 9394/1996, no governo de Fernando Henrique Cardoso (1995-2002), a Educação Profissional e Tecnológica ganha um capítulo próprio (CAMPOS ET AL., 2015), onde se separa o ensino médio do ensino profissional, passando essa última a ser oferecida nas formas subsequente e concomitante. 
Por meio da Lei 11.892/2008, no governo Lula (2003-2010), há uma grande transformação e expansão da Rede Federal de Educação Profissional e Tecnológica, com a criação de 38 Institutos Federais de Educação, Ciência e Tecnologia (ROSA; AMORIM; MACEDO, 2015). Para Costa (2019a), os Institutos apresentam objetivos mais próximos das demandas da população, com uma proposta diversificada na oferta do ensino da Educação Básica, Técnica, Tecnológica de Graduação e PósGraduação.

Desse modo, a Educação Profissional e Tecnológica se estabeleceu historicamente no Brasil de forma assistencialista e tecnicista, e nas décadas de 1990 e 2000 emergiram novas políticas educacionais para a EPT (LDB 9394/1996 e Lei 11.892/2008) com propostas de caráter emancipatório e indicativo de uma formação com perspectiva crítica e transformadora (COSTA, 2019b).

\subsection{Formação profissional e perfil do docente na Educação Profissional e Tecnológica}

Com a expansão da Rede Federal de Educação Profissional e Tecnológica, fez-se necessário trazer à tona a discussão a respeito da formação profissional do docente e o perfil exigido a esse docente na Educação Profissional e Tecnológica. Esses professores possuem formação didática e pedagógica? São bacharéis ou licenciados? As faculdades de educação e os cursos de Pedagogia oferecem em seus currículos componentes da EPT?

Os artigos encontrados nessa categoria explanam esse tema, respondendo a essas perguntas e levantando outras questões relevantes.

Carvalho e Souza (2014) afirmam que, com a criação dos Institutos Federais, tornou-se necessário debater sobre novas políticas públicas de formação para o docente de EPT, enfatizando que as faculdades de educação e o curso de Pedagogia devem estar presentes no processo de formação desse profissional. A pesquisa realizada pelos autores buscou conhecer o perfil docente de professores da Rede Federal de Educação Profissional e Tecnológica. Segundo eles, o que se 
percebe nesses docentes é uma formação fragmentada, improvisada e insuficiente do ponto de vista pedagógico e que, por mais que esses profissionais busquem suprir suas lacunas de formação no campo pedagógico, acabam se frustrando, já que os cursos oferecidos nas faculdades de educação focam a educação infantil e de nível fundamental.

Pinheiro e colaboradores (2015) corroboram com Carvalho e Souza (2014) ao dizer que os professores da Educação Profissional e Tecnológica buscam suprir a falta de preparo didático-pedagógico em programas de formação continuada, mas acabam desmotivados devido à falta de foco desses cursos em relação a questões didáticas voltadas para a EPT. Por esse motivo, esses profissionais valorizam mais a formação técnica do que a formação pedagógica. Segundo os autores, ainda, não tem como prescrever o que faz os professores desempenharem bem suas funções docentes, mas consideram importante alinhar a prática à teoria e os conhecimentos técnicos e pedagógicos à prática de reflexão.

Campos e colaboradores (2015) buscaram elencar os saberes docentes necessários aos professores da Educação Profissional e Tecnológica, mas perceberam que não há forma de se fazer isso. O que é possível e deve ser buscado pelos professores da EPT é:

valorização da formação humana integral; diálogo com a sociedade com vistas à qualidade de vida; conhecimento do mundo do trabalho, de questões técnicas específicas; diálogo com o pensar e o fazer pedagógico, convergindo para a superação da dicotomia entre a teoria e a prática e a capacidade de reflexão sobre a prática. (CAMPOS et al.., 2015, p. 8)

Souza (2017), por sua vez, investiga docentes da Educação Profissional e Tecnológica, com um percurso formativo específico, que serve como exemplo claro das situações apresentadas por essa categoria: os engenheiros como professores da EPT. Após entrevistar cinco engenheiros que atuam como professores em um instituto federal, o autor percebe que a entrada na carreira docente se dá de forma não planejada, apesar de alguns ressaltarem que sempre gostaram de lecionar. Esses docentes aprendem a ensinar com suas experiências cotidianas, seus interesses 
individuais, erros e acertos. No entanto, Souza (2017) defende que o professor, seja licenciado ou bacharel, "deve passar por um processo de formação específico, mesmo que o conhecimento ali obtido não seja absoluto, acabado, mas um entre tantos outros que ocorrerão no decorrer da vida desse profissional" (p. 74).

A formação profissional e o perfil docente também foram objetos de pesquisa de Souza e Souza (2018), que entrevistaram docentes de um Instituto Federal. Para os autores, o aumento de ofertas de cursos profissionais e tecnológicos aumentou a demanda de docentes, fazendo com que as instituições contratassem professores sem exigir a formação docente, como no caso dos professores engenheiros, exemplificados anteriormente. O resultado da pesquisa comprovou que um grande número de docentes não possui formação pedagógica e que os mesmos anseiam por uma qualificação que os auxiliem nas dificuldades e desafios presentes no contexto da sala de aula.

Por fim, dentro desse contexto de perfil docente e formação profissional dos professores cabe destacar a importância das faculdades de educação e cursos de Pedagogia se reinventarem e promoverem mudanças estruturais de ordem prática e teórico-epistemológica para responderem aos desafios que a Educação Profissional e Tecnológica requer (CARVALHO; SOUZA, 2014). Trata-se de considerar a EPT como forma de preparar para o mundo do trabalho complexo, para lidar com as novas tecnologias, com surgimento de um novo modo de produção de conhecimentos e o impacto disso nos sistemas de ensino. Além disso, é importante que esse docente saiba trabalhar com as diversidades, que promova a inclusão, que contextualize o conhecimento e promova uma formação crítica.

\subsection{Gestão da Rede Federal de Educação Profissional e Tecnológica}

Um fato interessante da análise empreendida neste estudo foi a quantidade de artigos encontrados sobre gestão e gerenciamento da Rede Federal de Educação Profissional e Tecnológica. Esses artigos foram publicados em revistas de administração e gestão, demonstrando o interesse de outras áreas em investigar a 
EPT.

Os trabalhos dessa categoria apresentam análises de equipes de trabalho e de implantações de novos processos de gestão em instituições de Educação Profissional e Tecnológica, visões de gestores sobre determinados assuntos ligados à Educação Profissional e Tecnológica e dificuldades e desafios enfrentados pelos gestores dessas instituições.

Rosa, Massukado e Stumpf (2015) fazem a análise da dinâmica de uma equipe de trabalho de uma unidade administrativa de um instituto federal, de forma a fornecer um diagnóstico do grupo estudado e do ambiente de trabalho. Segundo os autores, conhecer os pontos fortes e fracos da equipe e dos processos desenvolvidos dentro da unidade auxilia na tomada de decisões para melhorar o gerenciamento e desenvolvimento das atividades.

Da mesma forma, Beltrame e Alperstedt (2015) fazem o estudo de um instituto federal, buscando compreender o processo de construção e implantação de política de comunicação. As autoras afirmam que processos dessa natureza devem contar com a participação dos servidores, ou seja, ser uma construção coletiva, e que, tanto a etapa de construção, como de atualização devem ser incorporadas na rotina organizacional. Beltrame e Alperstedt (2015) ainda sugerem recomendações para a construção e atualização de políticas de comunicação, tendo como base a experiência do instituto estudado.

Araújo e Hypólito (2016) também investigam um instituto federal, buscando compreender o discurso do Ministério da Educação (MEC) em relação às políticas educacionais para a Educação Profissional e Tecnológica, como esse discurso é acolhido pelos documentos institucionais do instituto em estudo e como os gestores dessa instituição "constroem sentidos em seus processos cotidianos de (re)construção dessa política, quais suas motivações, como são construídas as relações e os movimentos de resistência." (ARAÚJO; HYPÓLITO, 2016, p. 249). Dessa forma, os autores discutem as possibilidades e limitações da autonomia institucional frente aos documentos legais e publicações oficiais do MEC. 
Mello, Melo e Mello Filho (2016), por sua vez, buscaram mapear as competências gerenciais de gestores da Rede Federal de Educação Profissional, Científica e Tecnológica integrantes do Fórum de Gestão de Pessoas, além de identificar os desafios cotidianos e os entendimentos sobre gestão por competências. Como resultado evidenciou-se que a prática da gestão por competências não acontece nas instituições de EPT e que são grandes os desafios dos gestores de pessoas, uma vez que, as demandas de trabalho aumentam e os servidores são cada vez mais escassos.

Por fim, Nunes e Souza (2018) investigam como a formação ética está representada na fala dos gestores pedagógicos da Rede Federal de Educação Profissional e Tecnológica. Entre as razões dadas pelos gestores para que essa formação aconteça estão os propósitos de garantir uma formação humana, uma formação profissional ou uma formação integral. O que se percebe, no entanto, é uma falta de diretrizes claras que possam guiar as ações de formação ética na EPT, levando-se em conta as questões do mercado de trabalho e os avanços científicos e tecnológicos.

Essa categoria teve como foco o gerenciamento das instituições de Educação Profissional e Tecnológica, apresentando questões organizacionais, dinâmicas de trabalho, desafios dos servidores públicos na administração dos institutos, visões dos gestores sobre as demandas da EPT e políticas impostas pelo governo.

\subsection{Recursos utilizados na Educação Profissional e Tecnológica}

Os trabalhos dessa categoria apresentam recursos tecnológicos utilizados na Educação Profissional e Tecnológica: a Educação a Distância (NASCIMENTO; RODRIGUES, 2014) e a Aprendizagem Móvel (FREITAS; DUARTE FILHO, 2018).

O primeiro artigo trata sobre a Educação Profissional e Tecnológica na modalidade a distância. Com a ampliação da EPT, a oferta de cursos a distância surge, a partir de 2007, como uma forma de expandir o acesso ao mundo do trabalho 
pelos jovens e adultos e a interiorização do ensino profissional, dando oportunidade de acesso àqueles que se encontram distanciados das escolas presenciais (NASCIMENTO; RODRIGUES, 2014). De acordo com Nascimento e Rodrigues (2014), a Educação a Distância (EaD) permite romper com limitações de tempo e espaço, permitindo a democratização do ensino profissional, além de conceber uma nova forma de ensinar e de aprender, de criar uma nova forma de lidar com as informações e com a tecnologia, de forma que surge um novo perfil de estudante. Os autores reconhecem, no entanto, que é preciso considerar que uma parcela significativa da população não possui acesso a computadores ou internet, fazendo-se necessário a constituição de polos de apoio presencial.

Assim como a Educação a Distância utiliza-se da tecnologia para proporcionar maior acesso à educação, a Aprendizagem Móvel apresentada por Freitas e Duarte Filho (2018), objetiva promover maior acessibilidade a informações e conhecimentos em qualquer lugar e momento, oportunizando o combate à desigualdade na educação. Trata-se de uma modalidade que utiliza os dispositivos e tecnologias móveis como ferramentas estratégicas para promover o ensino. A Educação Profissional e Tecnológica deve levar em consideração as mudanças que vem ocorrendo no mundo do trabalho e por isso, utilizar as tecnologias móveis, já tão utilizadas nesse setor, é uma forma de preparar os estudantes para lidar com as inovações tecnológicas. O estudo mostrou que a Aprendizagem Móvel está sendo inserida de forma lenta no contexto educacional da Educação Profissional e Tecnológica e que a sua utilização ainda é informal, ou seja, não faz parte dos projetos pedagógicos dos institutos e seu uso não é incentivado.

Os trabalhos dessa categoria revelam recursos aplicados aos processos de ensino da Educação Profissional e Tecnológica, seja para democratizar o acesso à EPT, já que a Educação a Distância e a Aprendizagem Móvel ultrapassam as barreiras do espaço e do tempo, seja para formar um novo perfil de estudantes, preparados para lidar com as inovações tecnológicas, presentes no mundo do trabalho. 
Revista Labor

Programa de Pós-graduação em Educação, Universidade Federal do Ceará

Fortaleza-CE-Brasil

alsor

\subsection{Atuação de psicólogos na Educação Profissional e Tecnológica}

A expansão da Rede Federal de Educação Profissional e Tecnológica provocou alterações dentro das instituições de ensino profissional e tecnológica e uma dessas mudanças foi a composição e forma de atuação dos profissionais que compõem o corpo técnico administrativo dessas instituições. Um profissional que ganhou destaque dentro dos Institutos Federais (IFs) foi o psicólogo, especialmente a partir de 2005 (TITON; ZANELLA, 2018), com leis que incluíram os psicólogos no quadro de pessoal destas instituições. Os trabalhos desta categoria tratam sobre as formas de atuação e identidade do psicólogo escolar dentro dos IFs.

Titon e Zanella (2018) fazem uma revisão da literatura sobre a psicologia escolar na Educação Profissional e Tecnológica, e destacam o aumento de publicações com essa temática desde 2008, quando foram criados os Institutos Federais. As autoras abordam, baseados nos trabalhos encontrados, sobre as questões e desafios da atuação dos psicólogos no campo da educação profissional e tecnológica, como, por exemplo, as práticas e modos de intervenção dos psicólogos, as expectativas dos mesmos quanto a atuação nos institutos, a formação desses profissionais, o ingresso deles nesse ambiente e as mudanças ocorridas nas instituições de ensino. De acordo com os estudos analisados por Titon e Zanella, os psicólogos atuam em processos de ensino, de aprendizagem, intervenções com estudantes, ações de assistência estudantil e orientação profissional. Apesar da grande maioria dos trabalhos tratarem sobre atuação dos psicólogos com foco nos discentes, alguns autores defendem que as práticas dos mesmos devem envolver programas educacionais, gestão, acompanhamento das práticas e políticas institucionais e pedagógicas do curso.

Também na direção de discutir sobre o papel dos psicólogos na educação profissional e tecnológica, Feitosa e Araújo (2018) realizaram uma pesquisa com os psicólogos escolares lotados em um Instituto Federal a fim de conhecer a formação desses profissionais, as concepções sobre psicologia escolar e a atuação dos mesmos no contexto da educação profissional e tecnológica. Quanto a formação, 
observa-se que a maioria dos psicólogos possuem enfoque na área de psicologia clínica e organizacional e que se tenta suprir as lacunas em relação à psicologia escolar por meio de cursos de aperfeiçoamento profissional e formação complementar. Em relação às concepções sobre psicologia escolar revela-se uma falta de clareza quanto a área, mas ao mesmo tempo uma busca pela identidade profissional dentro dos Institutos Federais por parte dos psicólogos. Quanto a atuação profissional, os IFs apresentam dois eixos: acompanhamento dos discentes com ações como "acolher as demandas educativas dos estudantes, disponibilizar espaços para escuta psicológica, participar das reuniões acadêmicas e envolver os responsáveis pelos estudantes no cotidiano da escola" (FEITOSA; ARAÚJO, 2018, p.188) e, participação nas políticas de assistência estudantil com trabalhos de concessão de benefícios sociais, de promoção de inclusão e desenvolvimento dos estudantes no percurso escolar.

Os dois trabalhos encontrados sobre psicologia escolar na educação profissional e tecnológica proporcionam uma discussão sobre a atuação dos psicólogos, que estão inseridos num contexto de transformações, definições e redefinições do corpo técnico administrativo das instituições de ensino profissional e tecnológico.

\subsection{Produções da Educação Profissional e Tecnológica}

Os trabalhos dessa categoria tratam sobre produções distintas referentes a Educação Profissional e Tecnológica. O primeiro - Propriedades Intelectuais da Rede Federal de Educação Profissional, Científica e Tecnológica - trata sobre os registros de produções (produtos, serviços ou processos) pelas instituições de EPT. Por sua vez, o segundo - Produtos educacionais na formação do mestre em educação profissional e tecnológica - discute sobre o produto educacional como trabalho de conclusão de curso do Mestrado Profissional em EPT da Rede Federal de Educação Profissional e Tecnológica.

Prado, Fernandez-Crehuet (2017) fazem um estudo sobre a concepção de 
novos processos, produtos, serviços e inovações que são desenvolvidas dentro da Rede de Educação Profissional e Tecnológica. Tratam, portanto, da propriedade intelectual das instituições de EPT registradas no Ministério da Agricultura, Pecuária e Abastecimento (MAPA) e no Instituto Nacional da Propriedade Industrial (INPI) do Brasil. Segundo os autores, os Núcleos de Inovação Tecnológica (NITs) são os responsáveis pela proteção das propriedades intelectuais geradas nas instituições, e, apesar de a implantação dos NITs não estar consolidada em toda a Rede Federal de Educação Profissional, Científica e Tecnológica, o que se constatou pela pesquisa foi um crescimento significativo e relevante das propriedades intelectuais das instituições de EPT, ou seja, um aumento da pesquisa aplicada dentro dessas instituições, fomentando a inovação tecnológica.

Já Pasqualli, Vieira e Castaman (2018) abordam sobre o produto educacional como forma de articular o ensino e a pesquisa. Como dito anteriormente, os docentes da EPT buscam uma formação continuada, já que sentem que a formação inicial não os prepara para atuar nessa modalidade. O curso de Mestrado Profissional em Educação Profissional e Tecnológica apresenta-se como uma opção para a continuidade da formação desse docente, uma vez que, trata-se de um curso voltado exclusivamente para essa modalidade e direcionada para a formação de profissionais capazes de desenvolver atividades de pesquisa relacionadas ao ensino. A elaboração de um produto educacional como trabalho de conclusão de curso deve

[...] possibilitar a formação de profissionais externos à academia que saibam desenvolver e utilizar a pesquisa para agregar valor às suas atividades profissionais, tendo uma análise crítica da prática do trabalho, fomentando o desenvolvimento e implementação da produção tecnológica. (PASQUALLI; VIEIRA; CASTAMAN, 2018, p. 116)

Ou seja, trata-se de formar profissionais que sejam capazes de incorporar a pesquisa ao seu cotidiano de sala de aula ou nos diferentes espaços educativos em que atuam dentro do contexto da EPT.

Apesar de tratarem sobre diferentes produções dentro do contexto da Educação Profissional e Tecnológica, os dois trabalhos dessa categoria apresentam 
questões referentes à produtos ou processos criados e desenvolvidos, seja para a educação ou para a indústria, com o foco no desenvolvimento profissional ou tecnológico, na intenção de aperfeiçoar o ambiente de trabalho, produtivo e social.

\subsection{Avaliação da Educação Profissional e Tecnológica}

Dentro do contexto da Educação Profissional e Tecnológica, o tema da avaliação foi destaque em dois trabalhos encontrados nessa pesquisa.

No primeiro artigo, Sousa et al (2019) fazem uma análise do desempenho das Instituições Federais de Educação Profissional, Científica e Tecnológica Brasileiras no Exame Nacional do Ensino Médio - ENEM, e comparam os resultados com instituições de esfera municipal, estadual e privada. De acordo com os autores, o desempenho na prova do ENEM das instituições da rede federal apresenta-se de modo geral, mais elevado quando comparado aos outros tipos de instituições, o que, segundo a pesquisa, pode ser justificado por alguns aspectos como: maior formação e capacitação de professores, infraestrutura e investimento nas instituições federais. Além disso, é evidenciado o fato das instituições da rede federal aplicarem testes de seleção para o ingresso em seus cursos e a coexistência dos diferentes níveis educacionais em uma mesma unidade, que pode influenciar de forma positiva no desenvolvimento da autonomia para a aprendizagem e no desempenho escolar.

Já o segundo trabalho identifica experiências de aplicação da Teoria de Resposta ao Item (TRI) na avaliação da educação profissional e tecnológica. Para Korb, Andrade e Freire (2019), existe uma lacuna na avaliação da educação profissional e tecnológica, uma vez que, não há um sistema de avaliação nacional nem metodologias que atendam a particularidade dessa modalidade de ensino. Os autores fizeram uma revisão sistemática da literatura para encontrar trabalhos que utilizassem a TRI na avaliação da EPT, pois, segundo eles, é importante avaliar o "saber fazer", com testes que avaliem as competências técnicas. A TRI pode ser escolhida para isso por possuir respaldo na comunidade científica e apresentar resultados possíveis de comparabilidade entre os sujeitos. Foram encontradas e 
analisadas cinco produções estrangeiras, demonstrando a ausência de um sistema de avaliação dessa natureza no Brasil.

Mesmo tratando de diferentes formas de avaliação da Educação Profissional e Tecnológica, os estudos dessa categoria demonstram que não existe metodologias ou sistemas de avaliações no Brasil voltadas especificamente para a EPT. Ao utilizar o ENEM para avaliar o desempenho dos estudantes das instituições federais, não é levado em conta as diferenças do ensino oferecido nessas instituições e nas escolas normais. Cabe refletir, portanto, formas de aproximar escolas municipais, estaduais e particulares destes institutos federais, já que o desempenho dessas instituições é melhor em um exame que é voltado para avaliar o ensino médio normal. Além disso, é importante pensar formas de avaliar as competências técnicas e práticas das escolas de EPT, como proposto no segundo trabalho.

\section{Principais autores e legislações que tratam sobre a EPT}

Além de compreender sobre os diversos temas que perpassam e são objetos de pesquisa dentro do campo da Educação Profissional e Tecnológica, o estudo aqui empreendido apresenta importância para se conhecer quais são os principais referenciais teóricos da EPT, ou seja, quem são pesquisadores e autores que vem pesquisando e discutindo sobre o assunto, e quais são as principais leis ou documentos oficiais que tratam sobre essa modalidade de ensino.

Após estudo de cada um dos textos e suas respectivas referências, é possível perceber que os autores mais citados ou utilizados como referencial teórico são: Gaudêncio Frigotto, Maria Ciavatta, Marise Nogueira Ramos, Lucília Regina de Souza Machado e Fernando Selmar Rocha Fidalgo. Conhecer os principais referenciais teóricos pode contribuir com futuras pesquisas e análises sobre a EPT.

Já as principais legislações que tratam sobre a EPT são: Lei n. 9.394, de 20 de dezembro de 1996, que estabelece as diretrizes e bases da educação nacional; e Lei $n^{\circ}$. 11.892, de 28 de dezembro de 2008, que institui a Rede Federal de Educação Profissional e Tecnológica e cria os Institutos Federais de Educação, Ciência e 
Tecnologia.

\section{Considerações Finais}

A elaboração desse artigo proporcionou a leitura de trabalhos científicos que vem sendo produzidos nos últimos anos no campo da Educação Profissional e Tecnológica. Conhecer sobre o que se fala sobre o assunto é um ponto de partida para novas pesquisas e análises.

Dentre os artigos selecionados, foram encontradas sete categorias diferentes de acordo com os temas tratados dentro da Educação Profissional e Tecnológica, propiciando o entendimento de forma mais abrangente sobre a EPT.

Primeiramente analisou-se estudos que tratavam sobre a constituição e configuração e transformação da Educação Profissional e Tecnológica. Os trabalhos dessa categoria possibilitaram construir uma linha do tempo da EPT ao longo dos governos no Brasil. Entre mudanças de concepções sobre a Educação Profissional e Tecnológica - a EPT para atender às demandas do mercado e da lógica capitalista ou a EPT como educação integral e emancipatória - o que se percebe é que nos últimos anos houve uma expansão da Rede Federal de Educação Profissional e Tecnológica, de maneira a atender diferentes níveis de ensino.

Esse fato tornou a Educação Profissional e Tecnológica um terreno fértil para novas pesquisas, gerando produções científicas que buscassem entender e responder as novas questões provocadas pela expansão da EPT. Dessa forma, também foram analisados trabalhos que tratam sobre a formação profissional e perfil do docente na EPT, sobre gestão e gerenciamento dentro dos institutos, sobre os recursos, produções e avaliações da EPT e sobre as transformações do corpo técnico administrativo das instituições de ensino profissional e tecnológico, que atualmente contam a atuação dos psicólogos.

Por fim, foram identificados os principais autores e legislações que tratam sobre a Educação Profissional e Tecnológica, de maneira a contribuir com futuras análises no âmbito da EPT. São diferentes focos temáticos, referenciais teóricos e 
Revista Labor

Programa de Pós-graduação em Educação, Universidade Federal do Ceará

Fortaleza-CE-Brasil

legislações, que juntos, permitem compreender sobre a Educação Profissional e Tecnológica.

\section{Referências}

AFONSO, A. M. M.; GONZALEZ, W. R. C. Educação Profissional e Tecnológica no PNE 2014- 2024: questões para o debate. Eccos Revista Científica, São Paulo, n. 36, p. 67-83, jan./abr. 2015.

AFONSO, A. M. M.; GONZALEZ, W. R. C. Educação Profissional e Tecnológica: análises e perspectivas da LDB/1996 à CONAE 2014. Ensaio: Avaliação e Políticas Públicas em Educação, Rio de Janeiro, v. 24, n. 92, p. 719-742, jul./set. 2016.

ARAUJO, J. J.; HYPÓLITO, Á. M. Novos significados para educação profissional e tecnológica no instituto federal sul-rio-grandense: a política de criação dos institutos. Revista Brasileira de Política e Administração da Educação, v. 32, n. 1, p. 247265, jan./abr. 2016.

BARDIN, L. Análise de Conteúdo (L. A. Reto \& A. Pinheiro, Trad.). São Paulo: Edições 70, 2016.

BELTRAME, M. M. de L. L.; ALPERStedT, G. D. Construção de política de comunicação em instituições de educação profissional, científica e tecnológica: uma proposta com base na experiência do IFSC. Navus - Revista de Gestão e Tecnologia, v. 5, n. 2, p. 14-26, abr./jun. 2015.

BRASIL. Centenário da rede federal de educação profissional e tecnológica. Brasília: Ministério da Educação, 2009.

BRASIL. Lei n. 11.892 de 28 de dezembro de 2008. Institui a Rede Federal de Educação Profissional, Científica e Tecnológica, cria os Institutos Federais de Educação, Ciência e Tecnologia, e dá outras providências.

BRASIL. Lei n. 5.692, de 11 de agosto de 1971. Fixa Diretrizes e Bases para o ensino de $1^{\circ}$ e $2^{\circ}$ graus, e dá outras providências.

BRASIL. Lei n. 8.948, de 8 de dezembro de 1994. Dispõe sobre a instituição do sistema nacional de educação tecnológica e dá outras providências. 
BRASIL. Lei n. 9.394, de 20 de dezembro de 1996. Estabelece as diretrizes e bases da educação nacional. LDB - Lei de diretrizes e bases da educação.

CAMPOS, A. T. et al. Os saberes docentes para a formação de professores da educação profissional e tecnológica. Revista de Estudos e Pesquisas sobre Ensino Tecnológico (EDUCITEC), Manaus, v. 1, n. 01, p. 1-9, 2015

CARVALHO, O. F. de; SOUZA, F. H. de M. Formação do docente da educação profissional e tecnológica no Brasil: um diálogo com as faculdades de educação e o curso de Pedagogia. Educação \& Sociedade, Campinas, v. 35, n. 128, p. 883-908, jul./set. 2014.

CIAVATTA, M. A Produção do Conhecimento sobre a Configuração do Campo da Educação Profissional e Tecnológica. HOLOS, v. 6, p. 33-49, out. 2016.

COSTA, D. V. Reflexões acerca da constituição de Educação Profissional e tecnológica (EPT) no Brasil. Brazilian Journal of Development, Curitiba, v. 5, n. 1, p. 801-813, jan. 2019a.

COSTA, D. V. Reflexões acerca da articulação entre o trabalho e a educação profissional e tecnológica no Brasil. Revista Thema, v. 16, n. 2, p. 435-446, jul. 2019b.

FEITOSA, L. R. C.; ARAUJO, C. M. M. O papel do psicólogo na educação profissional e tecnológica: contribuições da Psicologia Escolar. Estudos de psicologia, Campinas, v. 35, n. 2, p. 181-191, abr./jun. 2018.

FREITAS, P. C. de; DUARTE FILHO, N. F. Aprendizagem móvel: percepções quanto à utilização por docentes da educação profissional e tecnológica. Revista EDaPECI, São Cristóvão, v. 18, n. 2, p. 50-63, mai./ago. 2018.

KORB, T.; ANDRADE, D. F. de; FREIRE, P. de S. A Teoria de Resposta ao Item Aplicada em Avaliações da Educação Profissional e Tecnológica: uma revisão sistemática da literatura. Revista Meta: Avaliação, v. 11, n. 33, p. 773-792, dez. 2019.

LAKATOS, E. M.; MARCONI, M. de A. Fundamentos de metodologia científica. 5. ed. São Paulo: Atlas, 2003.

MELLO, P. T. S.; MELO, P. A. de; MELLO FILHO, R. T. Competências gerenciais evidenciadas e desejadas dos integrantes do fórum de gestão de pessoas da rede federal de educação profissional, ciência e tecnológica. RACE: Revista de 
Revista Labor

Programa de Pós-graduação em Educação, Universidade Federal do Ceará

Fortaleza-CE-Brasil

Administração, Contabilidade e Economia, Joaçaba: Ed. Unoesc, v. 15, n. 1, p. 349-374, jan./abr. 2016.

NASCIMENTO, C. O. do.; RODRIGUES, S. C. A Educação a Distância como Oportunidade de Formação Profissional e Tecnológica. RIED. Revista Iberoamericana de Educación a Distancia, v. 17, n 2, p. 151-171, 2014.

NUNES, V. B.; SOUZA, L. L. de. Formação Ética na Educação Profissional, Científica e Tecnológica. Educação \& Realidade, Porto Alegre, v. 43, n. 2, p. 711-726, abr./jun. 2018.

OLIVEIRA, A. P.; MATTA, L. Os conflitos entre os diferentes projetos de sociedade e os impactos na educação profissional tecnológica (EPT). Revista Brasileira de Planejamento e Desenvolvimento, Curitiba, v. 6, n. 2, p. 234-249, mai./ago. 2017.

PASQUALLI, R; VIEIRA, J de A; CASTAMAN, A. S. Produtos educacionais na formação do mestre em educação profissional e tecnológica. Revista de Estudos e Pesquisas sobre Ensino Tecnológico (EDUCITEC), Manaus, v. 4, n. 07, p. 106120, jun. 2018.

PINHEIRO, A. B. M. et al. Formação pedagógica de professores da educação profissional e tecnológica numa instituição Brasileira. Revista de Estudios e Investigación en Psicología y Educación, n. 6, p. 116-120, nov. 2015.

PRADO, J. L. do; FERNANDEZ-CREHUET, J. M.; JÚNIOR, A. M. de O. Propriedades Intelectuais da Rede Federal de Educação Profissional, Científica e Tecnológica. Arquivos Analíticos de Políticas Educativas, v. 25, n. 95, 2017.

ROSA, A. C. F.; AMORIM, J. M. M.; MACEDO, L. F. L. Contextualização do Instituto Federal do Tocantins na esfera das políticas de educação profissional e tecnológica. Revista de Gestão e Avaliação Educacional, v. 4, n. 7, p. 113-126, jan./jun. 2015.

ROSA, G. D. A.; MASSUKADO, L. M.; STUMPF, E. R. T. Análise de um Time de Trabalho à Luz do Framework Scrum: o caso de uma Organização Pública Federal de Educação Profissional e Tecnológica. HOLOS, v. 5, p. 338-349, out. 2015.

SOUSA, L. A. de et al. Desempenho das Instituições Federais de Educação Profissional, Científica e Tecnológica Brasileiras no ENEM. Tendências Pedagógicas, v. 34, p. 128-138, 2019. 
Revista Labor

Programa de Pós-graduação em Educação, Universidade Federal do Ceará

Fortaleza-CE-Brasil

SOUZA, F. das C. S. Percurso formativo de engenheiros professores da educação profissional e tecnológica. Revista Brasileira de Estudos Pedagógicos, Brasília, v. 98, n. 248, p. 62-76, jan./abr. 2017.

SOUZA, T. R. de A.; SOUZA, J. F. Formação Profissional e Perfil Docente da Educação Profissional e Tecnológica: Um Estudo no IFTM - Campus Paracatu. HOLOS, v. 3, p. 303-313, set. 2018.

TITON, A. P.; ZANELLA, A. V. Revisão de literatura sobre psicologia escolar na educação profissional, científica e tecnológica. Psicologia Escolar e Educacional, São Paulo, v. 22, n. 2, p. 359-368, mai./ago. 2018.

VOSGERAU, D. S. R.; ROMANOWSKI, J. P. Estudos de revisão: implicações conceituais e metodológicas. Revista Diálogo Educacional, Curitiba, v. 14, n. 41, jan./abr. 2014.

\begin{abstract}
Marina Chaves Silva
Belo Horizonte, MG, Brasil.

Mestranda no Programa de Pós-Graduação em Educação Tecnológica no Centro Federal de Educação Tecnológica de Minas Gerias (CEFET-MG). Possui especialização em Educação em Ciências (CECi) pela Faculdade de Educação da UFMG e graduação em Física pela Universidade Federal de Minas Gerais (UFMG) nas modalidades Bacharelado e Licenciatura. Atuou como professora no Projeto de Extensão de Ensino Médio de Jovens e Adultos - PEMJA da UFMG e atualmente trabalha como Técnico em Assuntos Educacionais na Universidade Federal de Minas Gerias.
\end{abstract}

Email: luiz. marinacsf11@gmail.com

Link do Lattes: http://lattes.cnpq.br/5975610786206840

\title{
Ivo de Jesus Ramos
}

Belo Horizonte, MG, Brasil.

Doutor em Ensino de Ciências e Matemática. Possui mestrado em Educação Tecnológica, Especialização em Educação, licenciatura em Física e Matemática. Graduado em Engenharia Química. Atualmente é Professor do Ensino Básico Técnico e Tecnológico do Centro Federal de Educação Tecnológica de Minas Gerais (CEFETMG).

Email: ivoramos@cefetmg.br

Link do Lattes: http://lattes.cnpq.br/3740726434108113

Recebimento: 02/06/2020

Aprovação: 26/08/2020 
Revista Labor

Programa de Pós-graduação em Educação, Universidade Federal do Ceará

Fortaleza-CE-Brasil

\section{Q.Code}

\section{Editores-Responsáveis}

Dr. Enéas de Araújo Arrais Neto, Universidade Federal do Ceará, UFC, Ceará, Brasil

Dr. Sebastien Pesce, Universidade de Orléans, França 